\title{
Oral bacteria and yeasts in relationship to oral ulcerations in hematopoietic stem cell transplant recipients
}

\author{
Alexa M. G. A. Laheij • Johannes J. de Soet • \\ Peter A. von dem Borne • Ed J. Kuijper • \\ Eefje A. Kraneveld • Cor van Loveren • \\ Judith E. Raber-Durlacher
}

Received: 8 August 2011 / Accepted: 2 April 2012 / Published online: 26 April 2012

(C) The Author(s) 2012. This article is published with open access at Springerlink.com

\begin{abstract}
Background Oral mucositis is a serious and debilitating side effect of conditioning regimens for hematopoietic stem cell transplant (HSCT). Through HSCT, the homeostasis in the oral cavity is disrupted. The contribution of the oral microflora to mucositis remains to be clarified. The aim of our study was to investigate the relationship between yeasts, bacteria associated with periodontitis, and oral ulcerations in HSCT recipients.

Methods This prospective observational study included 49 adult HSCT recipients. Twice weekly, oral ulcerations were scored, and oral rinsing samples were obtained. Samples were evaluated for the total bacterial load; the Gram-negative bacteria: Aggregatibacter actinomycetemcomitans, Porphyromonas gingivalis, Prevotella intermedia, Parvimonas micra, Fusobacterium nucleatum, Tannerella forsythia, and Treponema denticola; and the yeasts: Candida albicans, Candida
\end{abstract}

This paper was presented at the Supportive Care in Cancer MASCC/ ISOO 2011 International Symposium in Athens, Greece on 23-25 June 2011.

A. M. G. A. Laheij $(\bowtie) \cdot$ J. J. de Soet • E. A. Kraneveld •

C. van Loveren $\cdot$ J. E. Raber-Durlacher

Department of Preventive Dentistry,

Academic Center for Dentistry Amsterdam (ACTA),

University of Amsterdam and VU University,

Gustav Mahlerlaan 3004,

1081 LA Amsterdam, The Netherlands

e-mail: a.lahey@acta.nl

P. A. von dem Borne · J. E. Raber-Durlacher

Department of Hematology, Leiden University Medical Center,

P.O. Box 9600, 2300 RC Leiden, The Netherlands

\section{E. J. Kuijper}

Department of Medical Microbiology,

Leiden University Medical Center,

P.O. Box 9600, 2300 RC Leiden, The Netherlands glabrata, Candida kefyr, Candida krusei, Candida parapsilosis, and Candida tropicalis using real-time polymerase chain reaction with specific primers and probes. Explanatory variables for oral ulcerations were calculated using the multilevel generalized estimated equations (GEE) technique.

Results None of the samples was positive for A. actinomycetemcomitans, while $F$. nucleatum was found most often (66\% of samples). C. albicans was the most isolated yeast ( $88 \%$ of samples), whereas C. parapsilosis was found in only $8 \%$ of the samples. Multivariate GEE analyses identified $P$. gingivalis, $P$. micra, $T$. denticola, $F$. nucleatum, $C$. glabrata, and $C$. kefyr as significant explanatory variables of oral ulcerations.

Conclusions Our data indicate that $P$. gingivalis in particular, but also P. micra, T. denticola, F. nucleatum, C. glabrata, and $C$. kefyr may play a role in ulcerative oral mucositis in patients undergoing HSCT.

Keywords Oral ulceration · HSCT · Periodontal pathogens · Yeasts $\cdot$ Oral mucositis $\cdot$ Stomatitis

\section{Introduction}

Mucositis remains one of the most common, serious, and painful side effects of cytotoxic cancer therapy [1]. It is reported that between $76 \%$ and $89 \%$ of all patients receiving a myeloablative hematopoietic stem cell transplant (HSCT) experience oral mucositis [2-4]. Mucositis can be so painful that patients are not able to eat or drink, and it can result in a poorer treatment outcome [5].

The pathobiology of mucositis consists of five interdependent stages: initiation, the primary damage response (messaging and signaling), amplification of damage responses, ulceration, and finally, healing of the ulcers. Oral 
microorganisms are thought to be involved in the ulceration phase, where they probably are able to intensify the inflammatory process and aggravate or promote the formation of ulcers [6].

Most of the bacterial species present in the oral cavity are harmless commensal bacteria, and under normal healthy conditions, there is homeostasis in the oral cavity. In patients with cancer, this delicate balance can be disturbed by the cancer itself, the anti-cancer treatment, or by the supportive therapies that all may contribute to a shift in the oral microflora of the oral cavity from mainly Gram-positive to Gram-negative bacteria [7]. This disruption of the balance may be related to direct cytotoxic effect on the oral flora, granulocytopenia, altered salivary output, alteration in cytokine release, use of antibiotics, compromised oral hygiene, and the acquisition of hospital-associated pathogens [8]. In the cell wall of Gram-negative obligatory or facultative anaerobic bacteria including Actinomyces actinomycetemcomitans, Fusobacterium nucleatum, Porphyromonas gingivalis, Parvimonas micra, Prevotella intermedia, Treponema denticola, and Tannerella forsythia, components such as the endotoxin lipopolysaccharide (LPS) are present. LPS activates macrophages to produce inflammatory mediators like interleukin 1 (IL-1), interleukin 6 (IL-6), tumor necrosis factor-alpha (TNF- $\alpha$ ), prostaglandin $\mathrm{E} 2\left(\mathrm{PGE}_{2}\right)$, and matrix metalloproteinases (MMPs) [9]. These bacteria are associated with periodontitis and gingivitis, and they may have the ability to aggravate the inflammatory process in mucositis.

In addition, oral microbes and cytokines may enter the bloodstream when the integrity of the oral mucosal barrier is disrupted and may induce fever and infectious complications including sepsis [10-12]. Periodontal infections are also associated with fever and sepsis in patients treated with high-dose chemotherapy [13]. However, until now, it is unclear whether there is an association between periodontal pathogens and mucositis [8].

Candida species and particularly Candida albicans are also part of the commensal oral flora in a large part of the population. Between $20 \%$ and $75 \%$ of individuals in the general population is colonized with Candida species [14]. When the oral homeostasis is disrupted, Candida species may overgrow and cause local oral infection (candidiasis). Candidiasis can cause systemic infections and contributes highly to morbidity in infected patients [15]. Risk factors for oral candidiasis are immunosuppression, hyposalivation, local tissue damage, higher age, and wearing dentures [16-18]. HSCT recipients have several of these risk factors and are therefore at high risk for developing candidiasis and invasive Candida infection (candidemias). In a systematic review, oral yeast colonization is reported to occur in $73 \%$ of patients treated with high-dose chemotherapy, and candidiasis develops in $38 \%$ of these patients [16].
In addition to infections caused by $C$. albicans, infections may be caused by non-albicans Candida species such as Candida glabrata, Candida parapsilosis, Candida tropicalis, Candida krusei, and Candida kefyr as well [19]. Non-albicans Candida species are increasing and are estimated to account for $40-70 \%$ of today's systemic Candida infections in HSCT recipients with hematological malignancies. Risk factors for candidemias due to C. tropicalis and C. krusei include neutropenia and HSCT [20]. Although seldom found, C. kefyr has been linked to bloodstream infections in patients with hematological malignancies [21, 22]. A recently published study found an association between $C$. albicans and oral mucositis in patients receiving high-dose chemotherapy for hematological malignancies [23].

To the best of our knowledge, no studies have been performed in which HSCT patients with and without ulcerations were prospectively followed over time, and bacterial and fungal analysis of standardized samples was carried out using sensitive real-time polymerase chain reaction (PCR). The aim of this prospective, observational study was to investigate the relationship between bacteria associated with periodontitis, yeasts, and oral ulcerations in HSCT recipients using real-time PCR. Data on the relationship between several patient characteristics, herpes viruses, and oral ulcerations in the same patient group have been published elsewhere [24].

\section{Patients and methods}

\section{Patients}

Forty-nine adult patients that underwent HSCT were enrolled in this study. All patients were treated for hematological malignancies at the Leiden University Medical Center between November 2006 and June 2009. The study was approved by the Medical Ethical Committee of the Leiden University Medical Center, and patients gave their written informed consent.

T-cell-depleted stem cell transplantation was performed either with a myeloablative conditioning (MAC) or a reduced intensity-conditioning regimen (RIC) [25-27]. During granulocytopenia, all patients received oral digestive tract decontamination with oral neomycin, polymyxin, ciprofloxacin, and a neomycin-polymyxin paste or rinse. Antifungal prophylaxis consisted of oral amphotericin B tablets in combination with lozenges to be sucked on slowly. Antistreptococcal prophylaxis with intravenous benzylpenicillin was given 7 days following MAC and continued for 14 days. Pre-emptive antibiotics, consisting of vancomycin and ceftazidime, were administered when patients developed a fever. During hospitalization, all patients received 
standardized oral care aimed at preventing the accumulation of plaque and keeping the oral tissues moist.

Oral assessment and sampling

An oral assessment was performed at least twice weekly starting before or as soon as possible after the administration of the conditioning regimen until hospital discharge. Oral mucositis was scored according to the criteria of the World Health Organization [28] at eight non-keratinized anatomical sites (labial and buccal mucosa, floor of mouth, lateral and ventral tongue, and soft palate) by one trained dentist (J.E.R-D). Ulcerations present at the keratinized/specialized mucosa (vermillion borders of the lip, gingiva, dorsum of the tongue, and hard palate) were noted separately.

Oral rinsing samples were taken at each oral assessment using $10 \mathrm{ml}$ of $0.9 \%$ sterile saline solution. Patients were asked to rinse for $30 \mathrm{~s}$. Samples were frozen at $-20^{\circ} \mathrm{C}$ within $3 \mathrm{~h}$ and thereafter stored at $-80^{\circ} \mathrm{C}$ until analysis.

Bacterial and yeast load determination

A total number of 233 rinsing samples were collected, for $90 \%$ of patients varying between two to eight samples. All samples were thawed and concentrated ten times by freezedrying $1 \mathrm{ml}$ of sample and dissolving the residuum in $100 \mu \mathrm{l}$ of PCR water (Roche Diagnostics, Almere, The Netherlands). DNA was isolated from all samples with the MagNa Pure LC DNA Isolation Kit III for bacteria and fungi (Roche Diagnostics) using the MagNa Pure LC 2.0 instrument (Roche Diagnostics). Bacterial and yeast loads were determined in duplo by real-time PCR using the LightCycler ${ }^{\circledR}$ 480-II Instrument (Roche Diagnostics).

Loads of $A$. actinomycetemcomitans and $F$. nucleatum (reaction A); $P$. gingivalis and T. forsythia (reaction B); $P$. micra, $P$. intermedia, and $T$. denticola (reaction C); and $C$. albicans and PhHV [36] (reaction D) were determined by multiplex real-time PCR. PhHV served as an internal control for DNA extraction and PCR inhibition. Loads of $C$. glabrata, C. kefyr, C. krusei, C. parapsilosis, C. tropicalis, and the total bacterial load were determined by monoplex real-time PCR (Table 1). All PCRs were carried out in $20-\mu 1$ reaction volume containing $10 \mu \mathrm{l}$ of LightCycler $^{\circledR} 480$ Probes Master (Roche Diagnostics).

The samples for bacterial analysis were subjected to preincubation cycle of $95^{\circ} \mathrm{C}$ for $5 \mathrm{~min}$, followed by 45 cycles of quantification at $95^{\circ} \mathrm{C}$ for $10 \mathrm{~s}$ and at $60^{\circ} \mathrm{C}$ for $20 \mathrm{~s}$. The samples for Candida analysis were subjected to a preincubation cycle of $95^{\circ} \mathrm{C}$ for $10 \mathrm{~min}$, followed by 50 cycles of quantification at $95^{\circ} \mathrm{C}$ for $10 \mathrm{~s}$, at $60^{\circ} \mathrm{C}$ for $30 \mathrm{~s}$, and at $72^{\circ} \mathrm{C}$ for $30 \mathrm{~s}$.
Serial tenfold dilutions of homologous DNA were used as standard curves. For quantification, the results of the samples were calculated using the standard curve of the corresponding bacterium or yeast. For quantification of the total bacterial load, a standard curve of A. actinomycetemcomitans was used. PCR water was used as a negative control in every run.

\section{Statistics}

Loads are shown as CFU per milliliter of rinsing sample. To adjust for the unreliability of low positive signals in real-time PCR, the loads of these samples were set at $80 \%$ of the detection limit of the corresponding bacterium or yeast. To adjust for skewness of the data, ${ }^{10} \log$ transformed bacterial and yeast loads were used in the analysis. Mucositis scores were recalculated into binary scores: mucositis grade $0-1$ was scored as no ulceration present, and mucositis grades 2-4 were scored as ulceration present. It was not possible to look at different grades of mucositis as a dependent variable since some mucositis scores did not occur frequently enough. To be able to look at shifts in the oral cavity, the absolute loads of the bacterial and Candida species were recalculated into percentages/ratio in relation to the total bacterial load.

Explanatory variables of oral ulcerations were calculated using the multilevel binary logistic regression procedure called the generalized estimated equations (GEE) technique, with first order autoregressive correlation structure and a robust estimation procedure. Independent variables were screened as possible explanatory variables for oral ulcerations using univariate GEE analyses. An independent variable with a $p$ value $<0.20$ was entered in the multivariate GEE analysis. A $p$ value $<0.05$ was considered statistically significant. All statistical analyses were calculated using SPSS version 18.0.

\section{Results}

Patient characteristics and oral assessment outcomes

The characteristics of the 49 patients that participated in this study are summarized in Table 2. At 232 (out of 233) time points, WHO scores involving non-keratinized oral sites were recorded. Most of the patients (70\%) developed mucositis during their stay in the hospital. One patient developed mucositis grade 1 at most, 23 patients experienced peak mucositis of grade 2, seven patients developed ultimately grade 3 mucositis, and three patients suffered from a maximum of grade 4 mucositis. Furthermore, 25 patients $(51 \%)$ developed an ulceration on the keratinized/ specialized mucosa. At 226 (out of 233) time points, ulcerations on the keratinized mucosa were scored. 


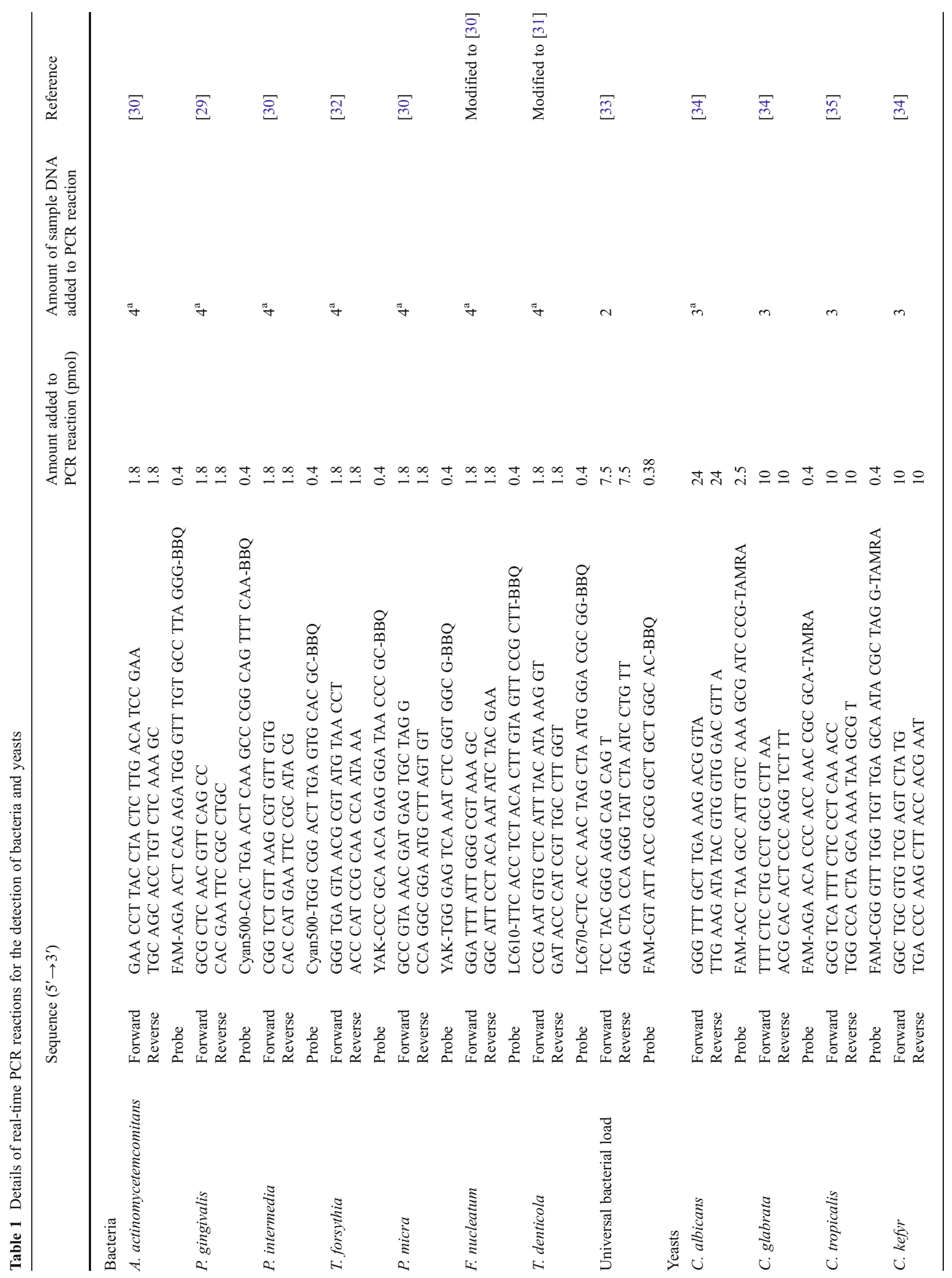


Table 2 Patient characteristics

\begin{tabular}{|c|c|}
\hline Number of patients & 49 \\
\hline Male & $27(55 \%)$ \\
\hline Female & $22(44 \%)$ \\
\hline Age (mean $\pm \mathrm{SD})$ & $48.8( \pm 13.6)$ years \\
\hline \multicolumn{2}{|l|}{ Diagnosis } \\
\hline Acute myeloid leukemia & $19(39 \%)$ \\
\hline Multiple myeloma & $10(20 \%)$ \\
\hline Acute lymphoblastic leukemia & $5(10 \%)$ \\
\hline Non-Hodgkin lymphoma & $5(10 \%)$ \\
\hline Myelodysplastic syndrome & $3(6 \%)$ \\
\hline Chronic myeloid leukemia & $2(4 \%)$ \\
\hline Hodgkin lymphoma & $2(4 \%)$ \\
\hline Chronic lymphocytic leukemia & $2(4 \%)$ \\
\hline Others & $1(2 \%)$ \\
\hline \multicolumn{2}{|l|}{ Donor type } \\
\hline Matched sibling & $17(35 \%)$ \\
\hline Matched unrelated & $25(57 \%)$ \\
\hline Others & $4(8 \%)$ \\
\hline \multicolumn{2}{|l|}{ Conditioning regimen } \\
\hline Myeloablative & $25(51 \%)$ \\
\hline Reduced intensity & $24(49 \%)$ \\
\hline Length of stay in the hospital (mean \pm SD) & $27( \pm 8.9)$ days \\
\hline
\end{tabular}

Oral bacterial load

The percentages of positive samples and positive patients and the measured ranges for the respective bacteria are shown in Table 3. A. actinomycetemcomitans could not be found in any of the samples. On the other hand, F. nucleatum was the bacterium that was found most often. All samples were positive for bacteria. The total load of periodontal bacteria as a proportion of the total bacterial load was $1.2 \%$ on average. In about $84 \%$ of the samples, the proportion of periodontal bacteria was lower than $1 \%$. In six samples, the proportion of periodontal bacteria was higher than $10 \%$, with a maximum of $63 \%$.

\section{Candida loads}

All patients had samples that were positive for a least one Candida species during treatment. Only $4 \%$ of the samples were negative for Candida species. Most patients were positive for a maximum of four different Candida species. The percentages of positive samples, patients, and the measured ranges of Candida loads are shown in Table 4. C. albicans was found most often, whereas $C$. parapsilosis was found the least.

In relationship to the total bacterial load, the ratio of the total Candida load was on average $2 \%$. There was no 
Table 3 Descriptives of the determined bacterial species

\begin{tabular}{llll}
\hline Bacterial species & $\begin{array}{l}\text { Percentage positive } \\
\text { samples }\end{array}$ & $\begin{array}{l}\text { Percentage positive } \\
\text { patients }\end{array}$ & Range $\left({ }^{10} \log \mathrm{CFU} / \mathrm{ml}\right)$ \\
\hline A. actinomycetemcomitans & 0 & 0 & 0 \\
P. gingivalis & $11 \%$ & $20 \%$ & $4.15-5.85$ \\
P. intermedia & $8 \%$ & $18 \%$ & $2.20-3.53$ \\
T. forsythia & $31 \%$ & $48 \%$ & $1.82-5.02$ \\
P. micra & $43 \%$ & $63 \%$ & $2.23-5.39$ \\
F. nucleatum & $66 \%$ & $86 \%$ & $3.23-5.63$ \\
T. denticola & $15 \%$ & $25 \%$ & $3.65-5.94$ \\
Total bacterial load & $100 \%$ & $100 \%$ & $4.0-8.38$ \\
\hline
\end{tabular}

significant correlation between the total bacterial load and the total Candida load (Pearson's rho=0.026, $p=0.718$ ).

Explanatory variables of oral ulcerations on non-keratinized mucosa

The bacterial and Candida species were represented as explanatory variables in three different ways. First, the presence or absence for each species was determined and entered in the GEE analyses. The univariate analyses are depicted in the second and third columns of Table 5. Independent variables with a $p$ value $<0.20$ in the univariate analyses were entered together in the multivariate analysis. When $P$. gingivalis or $C$. kefyr was present, the chance of having an ulceration on the non-keratinized mucosa was significantly higher.

Secondly, the absolute loads of all species were entered in the GEE analyses (see Table 5). The results of the multivariate analysis showed that also the load of $P$. gingivalis and $C$. kefyr were significant explanatory variables. The higher the load of $P$. gingivalis or $C$. kefyr, the higher the chance of an ulceration.

Thirdly, the percentages of bacterial and proportion of Candida species in relation to the total bacterial load were entered in the GEE analyses (see Table 5). In the multivariate analysis, the percentages of $P$. gingivalis, $P$. micra, $T$. denticola, F. nucleatum, and proportion of C. glabrata in relation to the total bacterial load turned out to be significant explanatory variables of oral ulcerations on the non- keratinized mucosa. The total bacterial and total Candida load were no significant explanatory variables of oral ulcerations on the non-keratinized mucosa.

Explanatory variables of oral ulcerations on keratinized mucosa

The bacterial and Candida species were represented as explanatory variables in the same way as for the analyses regarding ulcerations of the non-keratinized mucosa. The results of the GEE analyses are shown in Table 6. Looking at the presence of bacterial and Candida species in the multivariate analysis, $P$. gingivalis, $P$. micra, and $C$. kefyr were identified as significant explanatory variables of oral ulcerations. Also, the load of $P$. gingivalis and $C$. kefyr were significant explanatory variables. However, when the percentages of bacteria and proportions of Candida species in relation to the total bacterial load were considered, none of the possible explanatory species were significant in the multivariate GEE analysis. The total bacterial and total Candida load were no significant explanatory variables of oral ulcerations on the keratinized mucosa as well.

\section{Discussion}

The results of our study suggest that there is a relationship between several bacteria associated with periodontitis, yeasts, and oral ulcerations in HSCT patients. The most
Table 4 Descriptive properties of the determined Candida species

\begin{tabular}{llll}
\hline Yeasts & Percentage positive samples & Percentage positive patients & Range $\left({ }^{10} \log\right.$ CFU/ml $)$ \\
\hline C. albicans & $88 \%$ & $94 \%$ & $1.08-5.57$ \\
C. glabrata & $54 \%$ & $70 \%$ & $2.57-4.12$ \\
C. tropicalis & $58 \%$ & $80 \%$ & $1.86-4.44$ \\
C. kefyr & $56 \%$ & $94 \%$ & $1.18-1.57$ \\
C. krusei & $26 \%$ & $67 \%$ & $2.40-5.48$ \\
C. parapsilosis & $8 \%$ & $25 \%$ & $3.18-3.15$ \\
\hline
\end{tabular}


Table 5 Uni- and multivariate GEE analyses of predictors for ulcerations on the oral non-keratinized mucosa

\begin{tabular}{|c|c|c|c|c|}
\hline \multirow[t]{2}{*}{ Independent variable } & \multicolumn{2}{|c|}{$\begin{array}{l}\text { Univariate } \\
\text { analysis }\end{array}$} & \multicolumn{2}{|c|}{$\begin{array}{l}\text { Multivariate } \\
\text { analysis }\end{array}$} \\
\hline & $p$ value & $\exp (B)$ & $p$ value & $\exp (\mathrm{B})$ \\
\hline Presence $P$. gingivalis & 0.078 & 1.98 & $0.007 *$ & 3.36 \\
\hline Presence $P$. intermedia & 0.378 & 1.35 & & \\
\hline Presence $T$. forsythia & 0.022 & 0.45 & 0.115 & 0.48 \\
\hline Presence $P$. micra & 0.124 & 0.65 & 0.333 & 0.75 \\
\hline Presence F. nucleatum & 0.118 & 0.52 & 0.377 & 0.612 \\
\hline Presence $T$. denticola & 0.378 & 0.72 & & \\
\hline Presence $C$. albicans & 0.331 & 1.38 & & \\
\hline Presence $C$. glabrata & 0.969 & 0.99 & & \\
\hline Presence $C$. kefyr & 0.048 & 1.91 & $0.029 *$ & 2.01 \\
\hline Presence C. tropicalis & 0.492 & 1.18 & & \\
\hline Presence $C$. krusei & 0.422 & 1.38 & & \\
\hline Presence C. parapsilosis & a & & & \\
\hline Load $P$. gingivalis & 0.037 & 1.17 & $0.004 *$ & 1.37 \\
\hline Load $P$. intermedia & 0.086 & 1.23 & 0.355 & 1.22 \\
\hline Load $T$. forsythia & 0.103 & 0.85 & 0.073 & 0.77 \\
\hline Load $P$. micra & 0.068 & 0.82 & 0.056 & 0.78 \\
\hline Load $F$. nucleatum & 0.402 & 0.90 & & \\
\hline Load $T$. denticola & 0.559 & 0.94 & & \\
\hline Load C. albicans & 0.473 & 0.93 & & \\
\hline Load C. glabrata & 0.883 & 0.98 & & \\
\hline Load C. kefyr & 0.055 & 1.78 & $0.013^{*}$ & 2.056 \\
\hline Load C. tropicalis & 0.396 & 1.13 & & \\
\hline Load C. krusei & 0.336 & 1.16 & & \\
\hline Load C. parapsilosis & a & & & \\
\hline Total bacterial load & 0.254 & 0.86 & & \\
\hline Total Candida load & 0.975 & 1.00 & & \\
\hline Percentage $P$. gingivalis & 0.002 & 1.16 & $0.001 *$ & 1.372 \\
\hline Percentage $P$. intermedia & 0.852 & 0.46 & & \\
\hline Percentage $T$. forsythia & 0.563 & 0.94 & & \\
\hline Percentage $P$. micra & 0.059 & 0.11 & $0.001 *$ & 0.00 \\
\hline Percentage $F$. nucleatum & 0.099 & 1.44 & $0.015^{*}$ & 1.58 \\
\hline Percentage $T$. denticola & 0.000 & 0.98 & $0.000^{*}$ & 0.87 \\
\hline Percentage C. albicans & 0.143 & 1.07 & 0.080 & 1.07 \\
\hline Percentage $C$. glabrata & 0.081 & 1.65 & $0.000^{*}$ & 3.49 \\
\hline Percentage $C$. kefyr & 0.366 & & & \\
\hline Percentage C. tropicalis & 0.297 & 1.24 & & \\
\hline Percentage $C$. krusei & a & & & \\
\hline Percentage C. parapsilosis & a & & & \\
\hline
\end{tabular}

*Significant $(p<0.05)$

${ }^{a}$ Could not be determined because of insufficient power for the analysis of small strata

striking result was that the Gram-negative anaerobic bacterium $P$. gingivalis was a constant explanatory variable and had a positive predictive value for oral ulcerations. In
Table 6 Uni- and multivariate GEE analyses of predictors of ulcerations on the oral keratinized mucosa

\begin{tabular}{|c|c|c|c|c|}
\hline \multirow[t]{2}{*}{ Independent variable } & \multicolumn{2}{|c|}{$\begin{array}{l}\text { Univariate } \\
\text { analysis }\end{array}$} & \multicolumn{2}{|c|}{$\begin{array}{l}\text { Multivariate } \\
\text { analysis }\end{array}$} \\
\hline & $p$ value & $\exp (B)$ & $p$ value & $\exp (B)$ \\
\hline Presence $P$. gingivalis & 0.007 & 3.293 & $0.005^{*}$ & 4.38 \\
\hline Presence $P$. intermedia & 0.238 & 2.22 & & \\
\hline Presence $T$. forsythia & 0.741 & 0.923 & & \\
\hline Presence $P$. micra & 0.077 & 0.54 & $0.043^{*}$ & 0.46 \\
\hline Presence F. nucleatum & 0.657 & 0.854 & & \\
\hline Presence T. denticola & 0.924 & 0.959 & & \\
\hline Presence C. albicans & 0.539 & 0.746 & & \\
\hline Presence $C$. glabrata & 0.722 & 0.863 & & \\
\hline Presence C. kefyr & 0.082 & 0.587 & $0.005^{*}$ & 0.53 \\
\hline Presence C. tropicalis & 0.115 & 0.619 & 0.235 & 0.68 \\
\hline Presence C. krusei & 0.788 & 1.08 & & \\
\hline Presence $C$. parapsilosis & a & & & \\
\hline Load $P$. gingivalis & 0.011 & 1.29 & $0.034^{*}$ & 0.75 \\
\hline Load $P$. intermedia & 0.134 & 1.48 & 0.532 & 0.79 \\
\hline Load T. forsythia & 0.915 & 1.01 & & \\
\hline Load P. micra & 0.195 & 0.84 & 0.094 & 1.29 \\
\hline Load F. nucleatum & 0.611 & 0.95 & & \\
\hline Load T. denticola & 0.924 & 1.01 & & \\
\hline Load C. albicans & 0.368 & 0.85 & & \\
\hline Load C. glabrata & 0.883 & 0.97 & & \\
\hline Load C. kefyr & 0.047 & 0.57 & $0.028^{*}$ & 1.83 \\
\hline Load C. krusei & 0.728 & 1.04 & & \\
\hline Load C. tropicalis & 0.240 & 0.84 & & \\
\hline Load C. parapsilosis & a & & & \\
\hline Total bacterial load & 0.829 & 1.02 & & \\
\hline Total Candida load & 0.526 & 0.89 & & \\
\hline Percentage $P$. gingivalis & 0.514 & 0.94 & & \\
\hline Percentage $P$. intermedia & 0.846 & 2.57 & & \\
\hline Percentage $T$. forsythia & 0.979 & 1.00 & & \\
\hline Percentage $P$. micra & 0.715 & 0.46 & & \\
\hline Percentage $F$. nucleatum & 0.092 & 1.64 & 0.162 & 1.76 \\
\hline Percentage $T$. denticola & 0.117 & 1.06 & & \\
\hline Percentage $C$. albicans & 0.087 & 1.08 & 0.416 & 1.07 \\
\hline Percentage $C$. glabrata & 0.096 & 1.66 & 0.119 & 1.70 \\
\hline Percentage $C$. kefyr & 0.606 & 266.11 & & \\
\hline Percentage C. tropicalis & 0.307 & 2.14 & & \\
\hline Percentage $C$. krusei & 0.602 & 0.19 & & \\
\hline Percentage C. parapsilosis & 0.080 & 1.22 & 0.646 & 0.92 \\
\hline
\end{tabular}

*Significant $(p<0.05)$

${ }^{a}$ Could not be determined because of insufficient power for the analysis of small strata

addition, the anaerobic bacteria $P$. micra, F. nucleatum, and $T$. denticola and the yeasts $C$. glabrata and $C$. kefyr seemed to be related to oral ulcerations as well. 
The explanatory variables for ulcerations were calculated in three different ways, since microorganisms can be involved in infection or disease in different ways. Some microorganisms cause disease in small numbers, whereas other microorganisms need to be present in high numbers to provoke an infection. In addition, a shift in bacterial composition or the overgrowth of yeasts may be responsible for disease.

The GEE analysis is a multilevel regression method to determine the effect that independent variables have on dependent variables. The explanatory (independent) variables cannot be seen as causative factors. They explain, but do not cause the dependent variable, in this case oral ulcerations. Causative variables need to be present in time before the dependent variables. During the time of our study, a pre-transplant oral evaluation and sampling, including periodontal probing, was not part of the standard of care. Therefore, it was not possible to make such conclusions from this study.

No clear pattern or association between mucositis and the oral microflora emerges from literature [8]. However, it is difficult to compare studies since they differ on the populations that were studied, the chemotherapeutic regimens administered, the sampling and sample analysis methods, the microorganisms studied, the collection times, and the scoring methods for mucositis. Thus, it is difficult to compare our results to those of other studies. Moreover, the bacteria that we studied were not described previously in relation to mucositis. A. actinomycetemcomitans, P. gingivalis, Prevotella spp., and F. nucleatum were studied in children receiving chemotherapy, but none of these species was isolated [37]. The absence of A. actinomycetemcomitans in the present population is remarkable and may be due to the antibiotics used. However, in periodontitis patients, A. actinomycetemcomitans is usually not eradicated by these antibiotics. Approximately $15-30 \%$ of the normal population is positive for A. actinomycetemcomitans; thus, patients positive for A. actinomycetemcomitans were expected in our patient group as well. Although it cannot be excluded that A. actinomycetemcomitans was still present in subgingival biofilms, we do not have a good explanation for the absence of A. actinomycetemcomitans in the rinsing samples obtained from our patient group.

$P$. gingivalis was consistently associated with oral ulcerations in the present study and had a positive predictive value. $P$. gingivalis is present in $10-25 \%$ of healthy subjects and $53-90 \%$ in periodontitis patients [38, 39]. It possesses several virulence factors like fimbriae that enables the bacterium to attach to and invade into epithelial cells, the expression of proteases [40], and LPS and a polysaccharide capsule that are both highly antigenic and can induce the production of pro-inflammatory cytokines [41, 42]. These virulence factors might be able to prolong or intensify oral ulcerations or impair wound healing and that could explain the role of $P$. gingivalis in mucositis.

In addition, $P$. gingivalis may play a role in the initiation phase of mucositis. Chronic exposure to $P$. gingivalis may upregulate the expression of Toll-like receptors (TLR) on epithelial and endothelial cells in the oral mucosa. Increased expression of TLR may accelerate the initiation of mucositis when "CRAMPs" (endogenous damage-associated pattern molecules released by cells damaged by chemoradiation) bind to TLR resulting in activation of nuclear factor kappa-B (NF-kB) [43].

The role of herpes viruses in this patient group was described elsewhere [24]. There was no association between HSV-1 and $P$. gingivalis in these patients. So, the mechanism in which both microorganisms are involved in oral mucositis is thought to be different. Reactivation of herpes simplex virus type-I (HSV-1) in the oral cavity most probably causes oral ulcerations in HSCT patients, while $P$. gingivalis is supposed to be involved in the onset of mucositis and in maintaining or intensifying oral ulcerations.

We found high levels of colonization for all Candida species except for $C$. parapsilosis. The levels that we found were higher than those reported previously for $C$. albicans, and much higher for C. glabrata, C. tropicalis, $C$ krusei, $C$. kefyr, and $C$. parapsilosis in patients with hematological malignancies [17, 19]. Most patients were colonized with as much as four different Candida species. Others found at most two different yeast species in oral samples [18]. Most previous studies used traditional culturing methods, while we used sensitive real-time PCR. The detection level for Candida species in our samples was very low, also because we concentrated the samples ten times. The method we used probably explains the high level of colonization that we found. Furthermore, it is feasible that patients in this hospital have a high degree of colonization.

Only few studies link Candida species with oral mucositis or ulcerations in HSCT recipients [23, 44]. C. glabrata and C. kefyr have not been described as being associated to oral ulcerations before. A recently published study found an association between C. albicans and oral mucositis in patients receiving chemotherapy for hematological malignancies. In contrast to our study, in this study, patient samples in the absence of mucositis were not studied [23]. In children with acute lymphoblastic leukemia, an association between oral mucositis and Candida species has been found as well [44].

Although C. kefyr is considered to be a rare species, we found a very high colonization rate in our patient group (94\% of patients). Interestingly, the load in almost all samples was around the detection limit. Data on C. kefyr colonization are scarce; one study describes the high 
colonization rate of $C$. kefyr in patients with hematological malignancies [22]. Furthermore, there are case reports describing bloodstream infections with $C$. kefyr [21, 22], though invasive infections with this species are very rare at the LUMC. Most previous studies used traditional culturing methods, which are less sensitive than realtime PCR we have been using, and low loads could have been missed. It is also feasible that the primers and probe for $C$. kefyr reacted with another yeast as well. However, cross-reactivity tests in our lab did not reveal cross-reactivity of our primer-probe set with the other Candida species (C. albicans, C. glabrata, C. krusei, C. parapsilosis, C. tropicalis, and Candida dubliniensis). At the time of analysis in the laboratory, a search with the Basic Local Alignment Search Tool (BLAST) did not reveal cross reactivity with other yeasts as well. Thus, it seems plausible that this patient group had a high level of colonization with low loads of $C$. kefyr.

Despite anti-fungal and antibacterial prophylaxis, all patients were positive for Candida species, and bacterial loads were quite high. Resistance of Candida to amphotericin B, which was used prophylactically by our patient population, was probably not the reason why we found high levels of colonization, since most Candida species are not resistant to amphotericin B. However, some strains of $C$. krusei and C. kefyr have been reported to display resistance to amphotericin B [20]. A likely explanation may be a low compliance to the prophylactic scheme, since patients reported having difficulty sucking on the amphotericin B lozenges, particularly when having a dry mouth.

We were not surprised to find high numbers of bacteria despite antibiotic prophylaxis. Bacteria in an oral biofilm are difficult to eradicate with systemically administered antibiotics because the biofilm highly protects them against an attack. Furthermore, the bacteria in our study were relatively insensitive to the antibiotic prophylaxis used, and therefore, the bacterial load of the less sensitive organisms may become higher. Patients that developed a fever during neutropenia received an additional treatment with antibiotics that may have influenced the composition of the oral flora that we studied. In spite of all these antibiotic treatments, patients developed (ulcerative) mucositis, and the association with a part of the oral microflora was found.

In literature, there are conflicting results from studies that used antimicrobials to prevent oral mucositis [7]. These conflicting results may be due to the selection of inappropriate antimicrobials for the flora that is important to be eliminated (e.g., anaerobic Gram-negative bacteria), and the way of administering the antimicrobials (e.g., systemically versus locally) may affect the results as well.

In conclusion, $P$. gingivalis, in particular, but also $P$. micra, F. nucleatum, T. denticola, and the yeasts C. glabrata and $C$. kefyr are explanatory variables and have a positive predictive value for mucosal ulcerations in HSCT patients. Future studies on the role of these microorganisms in mucositis are warranted.

Acknowledgements The authors thank J.T. Ursem-Merks, M.P.W. de Graaff, and W.E.A.J. de Wit for technical support and H. Tran, E. Penders, N. Dekkers, P. Dekkers, W. Molenaar, T. Klemann, T. Garman, and $\mathrm{C}$. Verdegaal for assisting in the sample collection.

Conflicts of interest The authors declare no conflicts of interest.

Open Access This article is distributed under the terms of the Creative Commons Attribution License which permits any use, distribution, and reproduction in any medium, provided the original author(s) and the source are credited.

\section{References}

1. Sonis ST (2009) Mucositis: the impact, biology and therapeutic opportunities of oral mucositis. Oral Oncol 45(12):1015-1020

2. McGuire DB, Altomonte V, Peterson DE, Wingard JR, Jones RJ, Grochow LB (1993) Patterns of mucositis and pain in patients receiving preparative chemotherapy and bone marrow transplantation. Oncol Nurs Forum 20(10):1493-1502

3. Vagliano L, Feraut C, Gobetto G, Trunfio A, Errico A, Campani V, Costazza G, Mega A, Matozzo V, Berni M, Alberani F, Banfi MM, Martinelli L, Munaron S, Orlando L, Lubiato L, Leanza S, Guerrato R, Rossetti A, Messina M, Barzetti L, Satta G, Dimonte $\mathrm{V}$ (2011) Incidence and severity of oral mucositis in patients undergoing haematopoietic SCT (HSCT)-results of a multicentre study. Bone Marrow Transplant 46(5):727-732

4. Woo SB, Sonis ST, Monopoli MM, Sonis AL (1993) A longitudinal study of oral ulcerative mucositis in bone marrow transplant recipients. Cancer 72(5):1612-1617

5. Murphy BA (2007) Clinical and economic consequences of mucositis induced by chemotherapy and/or radiation therapy. J Support Oncol 5(9 Suppl 4):13-21

6. Sonis ST (2004) The pathobiology of mucositis. Nat Rev Cancer 4 (4):277-284

7. Donnelly JP, Bellm L, Epstein JB, Sonis ST, Symonds RP (2003) Antimicrobial therapy to prevent or treat oral mucositis. Lancet Infect Dis 3(7):405-412

8. Napeñas JJ, Brennan MT, Bahrani-Mougeot FK, Fox PC, Lockhart PB (2007) Relationship between mucositis and changes in oral microflora during cancer chemotherapy. Oral Surg Oral Med Oral Pathol Oral Radiol Endod 103(1):48-59

9. Page RC, Offenbacher S, Schroeder HE, Seymour GJ, Kornman KS (1997) Advances in the pathogenesis of periodontitis: summary of developments, clinical implications and future directions. Periodontol 14:216-248

10. Meurman JH, Pyrhönen S, Teerenhovi L, Lindqvist C (1997) Oral sources of septicaemia in patients with malignancies. Oral Oncol 33(6):389-397

11. Terhes G, Piukovics K, Urbán E, Nagy E (2011) Four cases of bacteraemia caused by Fusobacterium nucleatum in febrile, neutropenic patients. J Med Microbiol 60:1046-1049. doi:10.1099/jmm.0.026351-0

12. Raber-Durlacher JE, Epstein JB, Raber J, van Dissel JT, van Winkelhoff AJ, Guiot HF, van der Velden U (2002) Periodontal infection in cancer patients treated with high-dose chemotherapy. Support Care Cancer 10(6):466-473 
13. Peterson DE, Overholser CD (1981) Increased morbidity associated with oral infection in patients with acute nonlymphocytic leukemia. Oral Surg Oral Med Oral Pathol 51(4):390-393

14. Akpan A, Morgan R (2002) Oral candidiasis. Postgrad Med J 78 (922):455-459

15. Fraser VJ, Jones M, Dunkel J, Storfer S, Medoff G, Dunagan WC (1992) Candidemia in a tertiary care hospital: epidemiology, risk factors, and predictors of mortality. Clin Infect Dis 15(3):414-421

16. Lalla RV, Latortue MC, Hong $\mathrm{CH}$, Ariyawardana A, D'AmatoPalumbo S, Fischer DJ, Martof A, Nicolatou-Galitis O, Patton LL, Elting LS, Spijkervet FK, Brennan MT, Fungal Infections Section, Oral Care Study Group, Multinational Association of Supportive Care in Cancer (MASCC)/International Society of Oral Oncology (ISOO) (2010) A systematic review of oral fungal infections in patients receiving cancer therapy. Support Care Cancer 18 (8):985-992

17. Peterson DE (1992) Oral candidiasis. Clin Geriatr Med 8 (3):513-527

18. Schelenz S, Abdallah S, Gray G, Stubbings H, Gow I, Baker P, Hunter PR (2011) Epidemiology of oral yeast colonization and infection in patients with hematological malignancies, head neck and solid tumors. J Oral Pathol Med 40(1):83-89

19. Bagg J, Sweeney MP, Lewis MA, Jackson MS, Coleman D, Al MA, Baxter W, McEndrick S, McHugh S (2003) High prevalence of non-albicans yeasts and detection of anti-fungal resistance in the oral flora of patients with advanced cancer. Palliat Med 17(6):477-481

20. Krcmery V, Barnes AJ (2002) Non-albicans Candida spp. causing fungaemia: pathogenicity and antifungal resistance. J Hosp Infect 50(4):243-260

21. Reuter CW, Morgan MA, Bange FC, Gunzer F, Eder M, Hertenstein B, Ganser A (2005) Candida kefyr as an emerging pathogen causing nosocomial bloodstream infections in neutropenic leukemia patients. Clin Infect Dis 41(9):1365-1366

22. Sendid B, Lacroix C, Bougnoux ME (2006) Is Candida kefyr an emerging pathogen in patients with oncohematological diseases? Clin Infect Dis 43(5):666-667

23. Chen YK, Hou HA, Chow JM, Chen YC, Hsueh PR, Tien HF (2011) The impact of oral herpes simplex virus infection and candidiasis on chemotherapy-induced oral mucositis among patients with hematological malignancies. Eur J Clin Microbiol Infect Dis 30(6):753-759

24. Van der Beek MT, Laheij AMGA, Raber-Durlacher JE, Von dem Borne PA, Wolterbeek R, Van der Blij-de Brouwer CS, van Loveren C, Claas ECJ, Kroes ACM, de Soet JJ, Vossen ACTM (2012) Viral loads and antiviral resistance of herpesviruses and oral ulcerations in hematopoietic stem cell transplant recipients. Bone Marrow Transplant. doi:10.1038/bmt.2012.2

25. Barge RM, Brouwer RE, Beersma MF, Starrenburg CW, Zwinderman AH, Hale G, Waldmann $\mathrm{H}$, den Ottolander GJ, Falkenburg JH, Willemze R, Fibbe WE (2001) Comparison of allogeneic $\mathrm{T}$ cell-depleted peripheral blood stem cell and bone marrow transplantation: effect of stem cell source on short- and long-term outcome. Bone Marrow Transplant 27(10):1053-1058

26. Barge RM, Osanto S, Marijt WA, Starrenburg CW, Fibbe WE, Nortier JW, Falkenburg JH, Willemze R (2003) Minimal GVHD following in-vitro $T$ cell-depleted allogeneic stem cell transplantation with reduced-intensity conditioning allowing subsequent infusions of donor lymphocytes in patients with hematological malignancies and solid tumors. Exp Hematol 31 (10):865-872
27. Kalpoe JS, van der Heiden PL, Vaessen N, Claas EC, Barge RM, Kroes AC (2007) Comparable incidence and severity of cytomegalovirus infections following $\mathrm{T}$ cell-depleted allogeneic stem cell transplantation preceded by reduced intensity or myeloablative conditioning. Bone Marrow Transplant 40(2):137-143

28. World Health Organization (1979) Handbook for reporting results of cancer treatment. WHO, Geneva, pp 16-17

29. Boutaga K, van Winkelhoff AJ, Vandenbroucke-Grauls CM, Savelkoul PH (2003) Comparison of real-time PCR and culture for detection of Porphyromonas gingivalis in subgingival plaque samples. J Clin Microbiol 41:4950-4954

30. Boutaga K, van Winkelhoff AJ, Vandenbroucke-Grauls CM, Savelkoul PH (2005) Periodontal pathogens: a quantitative comparison of anaerobic culture and real-time PCR. FEMS Immunol Med Microbiol 45:191-199

31. Kuboniwa M, Amano A, Kimura KR, Sekine S, Kato S, Yamamoto Y, Okahashi N, Iida T, Shizukuishi S (2004) Quantitative detection of periodontal pathogens using real-time polymerase chain reaction with TaqMan probes. Oral Microbiol Immunol 19(3):168-176

32. Shelburne CE, Prabhu A, Gleason RM, Mullally BH, Coulter WA (2000) Quantitation of Bacteroides forsythus in subgingival plaque comparison of immunoassay and quantitative polymerase chain reaction. J Microbiol Methods 39(2):97-107

33. Nadkarni MA, Martin FE, Jacques NA, Hunter N (2002) Determination of bacterial load by real-time PCR using a broad-range (universal) probe and primers set. Microbiology 148:257-266

34. Guiver M, Levi K, Oppenheim BA (2001) Rapid identification of Candida species by TaqMan PCR. J Clin Pathol 54(5):362-366

35. Kraneveld EA, Crielaard W, Visser M, de Soet JJ (2012) Quantitative real-time PCR detection of differential Candida species in saliva of a healthy elderly population. (submitted)

36. Niesters HGM (2001) Quantitation of viral load using real-time amplification techniques. Methods 25:419-429

37. Sixou JL, De Medeiros-Batista O, Gandemer V, Bonnaure-Mallet M (1998) The effect of chemotherapy on the supragingival plaque of pediatric cancer patients. Oral Oncol 34(6):476-483

38. Griffen AL, Becker MR, Lyons SR, Moeschberger ML, Leys EJ (1998) Prevalence of Porphyromonas gingivalis and periodontal health status. J Clin Microbiol 36(11):3239-3242

39. Klein MI, Gonçalves RB (2003) Detection of Tannerella forsythensis (Bacteroides forsythus) and Porphyromonas gingivalis by polymerase chain reaction in subjects with different periodontal status. J Periodontol 74(6):798-802

40. Amano A (2000) (2010) Bacterial adhesins to host components in periodontitis. Periodontol 52(1):12-37

41. Pathirana RD, O'Brien-Simpson NM (2000) Reynolds EC (2010) Host immune responses to Porphyromonas gingivalis antigens. Periodontol 52(1):218-237

42. Vernal R, León R, Silva A, van Winkelhoff AJ, Garcia-Sanz JA, Sanz M (2009) Differential cytokine expression by human dendritic cells in response to different Porphyromonas gingivalis capsular serotypes. J Clin Periodontol 36(10):823-829

43. Sonis ST (2010) New thoughts on the initiation of mucositis. Oral Diseases 16(7):597-600

44. de Mendonça RM, de Araújo M, Levy CE, Morari J, Silva RA, Yunes JA, Brandalise SR (2012) Prospective evaluation of HSV, Candida spp., and oral bacteria on the severity of oral mucositis in pediatric acute lymphoblastic leukemia. Support Care Cancer 20(5):1101-1107. doi:10.1007/s00520-011-1190-0 